\section{Controlling Greenhouse Ventilation Inlets by Pressure Difference}

\author{
Louis D. Albright'
}

Additional index words. air distribution, wind effects, design

Summary. Computerized control of the greenhouse climate has increased the importance of air distribution and mixing. This report reviews the fluid mechanics of air flow through ventilation inlets and external pressures imposed by winds and applies the analyses to suggest methods of inlet control that improve traditional greenhouse ventilation. The suggested improved control has been implemented in a five-section research greenhouse on the Cornell University campus and has improved climate control significantly during ventilation. Potential pitfalls in implementing the improved control methods are discussed.

$M$

echanical ventilation can be divided into three types: negative-, positive-, and neutral-pressure ventilation. Negativepressure systems use fans to exhaust air, thereby creating a slight partial vacuum that draws fresh air in from outdoors. Negative-pressure ventilation systems are used most commonly for greenhouses in the United States and are well-suited for simple ventilation and evaporative cooling. Positivepressure ventilation accomplishes the reverse. Fans force air into the air space, creating a slight over-pressure and expelling air from the air space through outlets located in the greenhouse walls or roof. Positive-pressure ventilation systems also are suited to simple ventilation and evaporative cooling. Neutral-pressure systems are less

${ }^{1}$ Professor of agriculture and biological engineering, Department of Agricultural and Biological Engineering, Riley-Robb Hall, Cornell University, Ithaca, NY 14853-5701.

The cost of publishing this paper was defrayed in part by the payment of page charges. Under postal regulations, this paper therefore must be be hereby marked advertisement solely to indicate this fact. common and include two sets of fans, one to force air into the air space and one to exhaust air at the same rate. The result is an air pressure indoors that is about equal to the air pressure outdoors. Because neutral-pressure ventilation requires two sets of fans to create the same rate of ventilation, they are considered only when neutral pressure in the ventilated space is essential.

Within the context of this paper, mechanical ventilation is assumed to be of the exhaust (negative-pressure) type. It is assumed that the fans are controlled based on indoor air temperature and are staged from a minimum to some maximum ventilation rate. Stepped fan stages are typical, but what follows also applies to ventilation systems designed around variable-speed fans.

Many forces (pressures) interact to determine ventilation rates and air distribution patterns within mechanically ventilated greenhouses. Ventilation control in animal housing has been based on maintaining a controlled pressure difference between indoors and outdoors. The same has not been true of greenhouses. When a controlled pressure difference is not maintained, wind can seriously impair ventilation effectiveness. Additionally, a controlled pressure difference permits some airspeed control as fresh air enters the inlets. The objective of this report is to demonstrate the advantages of ventilation-inlet control to create a negative pressure difference that limits wind effects and to suggest design and operating standards for such control.

Ventilation-inlet control by pressure difference is applicable to large and small greenhouses. Wind effects in a small greenhouse can cause unstable temperature control by rapidly altering the microclimate in the vicinity of the temperature sensor and by causing temperature nonuniformity within the air space. Wind may not affect the temperature sensor directly in a large humidity).

Elevation above sea level ( $\mathrm{ft}$ Standard air density $\left(\mathrm{lb} / \mathrm{ft}^{3}\right)$

$-1000$

0.0774

0

1000

2000

0.0743

3000

0.0718

4000

0.0693

6000

0.0668

10,000 greenhouse, but it can cause significant temperature nonuniformity within the air space. In greenhouses of any cold outdoor air entering vents will mix and temper much more air flow rate ) entering through a wide opening at low velocity.

\section{Analysis of wind-pressure}

Aside from the action of fans, the primary agent leading to short-term air-pressure fluctuations across a building shell is wind. The blocking effect windward side on above atward side, and at corners and the peak, suction (acceleration forces) creates regions of a slight partial vacuum. The partial pressures are small compared to atmospheric pressure, but are critical openings in a

An extensive literature exists that can be used to estimate the actual pressures exerted on buildings by wind (e.g., Hoxley and Moran, 1983). Concern for wind pressures as structural (live) loads on buildings and the efventilation has led to the cre1) wind speed building shell. Wind direction usually is taken as parallel to one of the two main axes of a building, often perpendicular (transverse) to the long axis.

Wind-pressure effects are based stagnation pressure of the wind is totally blocked. When the wind is blocked, kinetic energy represented by its speed is converted entirely into a pressure. Total energy is conserved. form of potential energy, the static 
The magnitude of the over-pressure may be calculated by a well-known relationship from fluid dynamics, the Bernoulli Equation, as follows:

$$
\Delta P=0.4135 \rho \frac{V_{w}^{2}}{2 g}
$$

where $\Delta$ Pis the static over-pressure (inches of water column) created by blocking the wind completely, is air density $\left(\mathrm{lb} / \mathrm{ft}^{3}\right), g$ is the gravitational constant $\left(32.2 \mathrm{ft} / \mathrm{sec}^{2}\right)$, and $V_{w}$ is wind
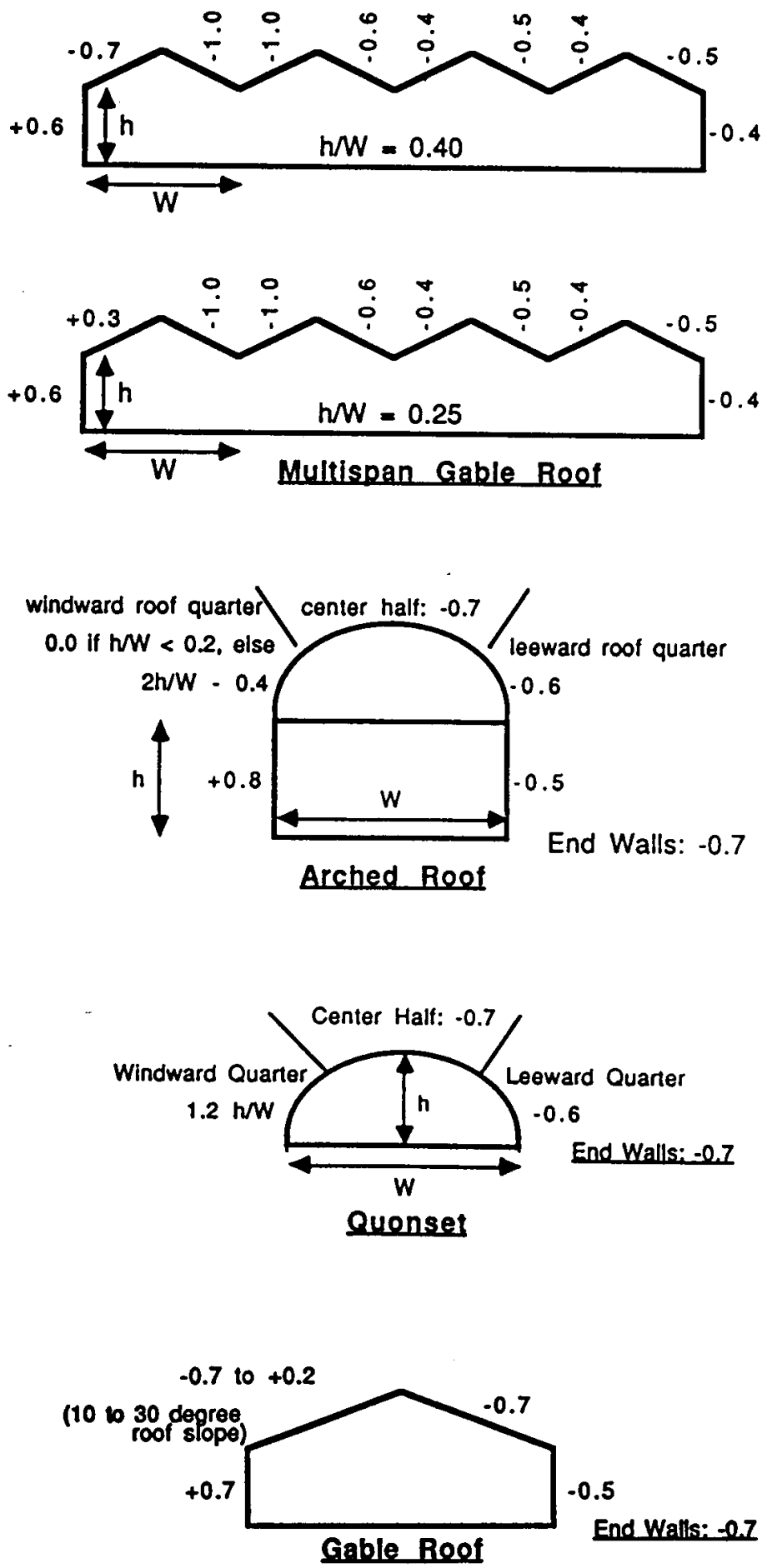

Fig. 1. Typical greenbouse shapes and associated wind-pressure coefficients. (Albright, 1990),
When blockage is not total, the wind pressure is less than calculated by Eq. [1]. Wind-pressure coefficients are defined as the ratio of the actual wind pressure to the wind pressure calculated by Eq. [1]. Wind-pressure coefficients can range from 1.0 to -1.0 , where negative values indicate suction (as on the leeward side of a greenhouse). Estimated values of wind-pressure coefficients for several standard greenhouse shapes are shown in Fig. 1 (Albright, 1990). Wind-pressure coefficients shown in Fig. 1 assume that the wind approaches the greenhouse transverse to the line of the roof peak. Using the wind-pressure coefficient, the actual wind effect is calculated as

$$
\Delta P=0.4135 c_{p} \rho \frac{V_{w}^{2}}{2 g}
$$

or, in a more convenient computational form,

$$
\Delta P=0.00642 c_{p} \rho V_{w}^{2}
$$

where $c_{p}$ is the wind-pressure coefficient (dimensionless). Calculated wind pressures are compiled in Table 2 for a range of wind speeds and wind-pressure coefficient values. Negative windpressure values yield negative wind pressures of identical magnitudes.

Consider a wind speed of $15 \mathrm{mph}$ and the resulting pressure on the downwind side of a greenhouse, where the wind-pressure coefficient is -0.6 . Suction pressure at that location is -0.064 inches water column. Unless the fans can create a negative pressure greater than -0.064 inches water column, inlets located on the downwind side act as outlets. Air is drawn out of the greenhouse through those vents, because the air pressure outdoors is lower than indoors, and air moves from regions of higher to lower pressure.

It should be emphasized that wind speeds and directions are never steady. Gustiness and sudden changes of direction (within at least a 45-degree approach angle) characterize windy days. Gustiness creates sudden changes of wind pressures at vent openings. In certain conditions, greenhouse vent openings have been observed to breathe, that is, air enters through a vent one moment and exits the greenhouse through the same vent the next. Further, sudden changes of wind direction lead to rapid changes in the values of wind-pressure coefficients, even to the extent of their alternating between negative and positive values if 
the wind approaches the greenhouse at an angle. Such effects lead to rapid changes of the microclimate near the vents. This can be a problem for plants near the vents, but the situation is exacerbated when temperature sensors are located in such microclimate areas. Small greenhouses are particularly sensitive to this difficulty.

Modern climate-control systems, centered on computers, typically use temperature sensors of small thermal mass placed inside aspirated containers. Its small thermal mass and close coupling to air temperature makes a small sensor highly responsive to sudden changes of air temperature. Rapid variations of the local microclimate can lead to highly inappropriate swings in the control mode. Dealing with this phenomenon in a research greenhouse at Cornell Univ. was the motivation for this report.

\section{Air flow through inlets}

The Bernoulli Equation can be inverted to calculate the speed of air as it moves through an inlet in response to an imposed pressure difference as follows [American Society for Heating, Refrigerating, and Air-Conditioning Engineers (ASHRAE), 1993]:

$$
V_{i}=\sqrt{\frac{2 g \Delta P}{\rho}}
$$

Inlet air velocity multiplied by the area of an inlet yields the maximum possible air-flow rate $(\mathrm{cfm})$ through the inlet. Inlets are not perfect and actual air flow rates through them are less than the ideals determined using the Bernoulli Equation. The ratio between actual and ideal air flow rates is the coefficient of discharge, $c_{d}$, and the air-flow rate, $Q$ can be calculated from

$$
Q=c_{d} A_{i} \sqrt{\frac{2 g \Delta P}{\rho}}
$$

or, in computational form for $Q$ (cfm)

$$
Q=1096 c_{d} A_{i} \sqrt{\Delta P / \rho}[6]
$$

where $A_{i}$ is the actual (measured) area of the inlet $\left(\mathrm{ft}^{2}\right)$. The value of $\mathrm{c}_{\mathrm{d}}$ is often found to be about 0.6.

\section{Fan pressure characteristics}

Almost all fans used for greenhouse ventilation are the propeller type. This type of fan moves the greatest amount of air for the least energy input. The penalty for using propeller fans is that they cannot work against large pressure differences (compared to centrifugal fans, for example). However, this is not a disadvantage for greenhouse ventilation because greenhouses are single air spaces and air distribution is not through ducts and diffusers, which induce substantial pressure drops in air flowing through them.

Fans can be characterized by their curve, which is a graph of airflow from the fan as a function of the pressure drop imposed across the fan. Fan system designers typically graph this curve with air flow as the $\mathrm{x}$-axis and pressure drop as the $y$-axis, but, for purposes of greenhouse ventilation-system design, it is more appropriate to reverse their traditional form. Fan curves are obtained using calibrated wind tunnels and have a typical shape as shown in Fig. 2 (ASHRAE, 1992). The fan curve intercepts the $y$-axis at a condition termed free air and the $\mathrm{x}$-axis at a condition termed cutoff. Fan cutoff is often at a static pressure difference of at least 0.4 inches water column, far beyond any pressure difference that could be tolerated in a greenhouse without causing potential structural problems and, as a minimum, difficulty in opening and closing doors.

It is unlikely that static pressures above 0.1 inches water column could be produced in a ventilated greenhouse-greenhouses are not sufficiently air-tight. Thus, and this is im-

Table 2. Wind pressures (inches of water column) at sea level as a function of wind speed and wind-pressure coefficient (at $70 \mathrm{~F}$ and $50 \%$ relative humidity).

\begin{tabular}{lccccccc}
\hline & \multicolumn{7}{c}{ Wind-pressure coefficient values } \\
\cline { 2 - 8 } Wind speed (mph) & $\mathbf{0 . 1}$ & $\mathbf{0 . 2}$ & $\mathbf{0 . 3}$ & $\mathbf{0 . 4}$ & $\mathbf{0 . 5}$ & $\mathbf{0 . 6}$ & $\mathbf{0 . 7}$ \\
\hline $\mathbf{5}$ & 0.001 & 0.002 & 0.004 & 0.005 & 0.006 & $\mathbf{0 . 0 0 7}$ & $\mathbf{0 . 0 0 8}$ \\
10 & 0.005 & 0.020 & 0.014 & 0.019 & 0.024 & $\mathbf{0 . 0 2 9}$ & $\mathbf{0 . 0 3 3}$ \\
$\mathbf{1 5}$ & 0.011 & 0.021 & 0.032 & 0.043 & 0.054 & 0.064 & $\mathbf{0 . 0 7 5}$ \\
$\mathbf{2 0}$ & 0.019 & 0.038 & 0.057 & 0.076 & 0.095 & 0.114 & $\mathbf{0 . 1 3 4}$ \\
25 & 0.030 & 0.060 & 0.089 & 0.119 & 0.149 & 0.179 & $\mathbf{0 . 2 0 9}$ \\
30 & 0.043 & 0.086 & 0.129 & 0.172 & 0.215 & 0.258 & $\mathbf{0 . 3 0 1}$ \\
50 & 0.119 & 0.239 & 0.358 & 0.477 & 0.596 & 0.716 & 0.83 \\
\hline
\end{tabular}

portant for ventilation-system design, greenhouse ventilation fans can be expected always to operate in the region near the free-air intercept, a region where the air flow rate is relatively insensitive 'to the pressure difference. That is, the ventilation rate will not be reduced significantly if pressure differences up to 0.1 inches water column are encountered. This has led to a generally accepted rule for such ventilation systems-fans (alone) control the ventilation rate and inlets (alone) control the fresh air's entering speed, distribution, and mixing.

\section{Fan and inlet interactions}

Equation [6] expresses the relationship between pressure difference and air flow through air inlets. Figure 2 shows the relationship between pressure difference and air flow through fans. A greenhouse is usually one large air space with the same pressure every where in the space. Thus, indoor air pressure at the inlets is the same as at the entrance to the fans. If there is no wind, the pressure difference across the inlets is the same as across the fans. If there is a wind, each inlet faces a possibly different pressure difference, as does the fan. However, the fan curve suggests that wind will impose little change on the air delivery of the fans. The same is not true of the inlets, as shown by Eq. [6].

First, consider how fans and inlets interact when there is no wind. Fans and inlets comprise a system, and their interactions can be shown by an example system-characteristic graph ( Fig. $3)$. The fan data, staging, and vent areas were chosen strictly for discussion and are not intended to suggest any specific greenhouse ventilationsystem design. The system graph includes only a selection of possible vent areas as examples-vents are typically continuously adjustable. Intersections of fan curves and inlet curves describe points of possible system operation, for the fans and inlets together experience the same pressure difference and the same air-flow rates. The only points where both balance are at intersections.

Consider a ventilation control sequence, where fan stage 2 operates steadily and the inlet area slowly increases from vent area 1 to vent area 3 . The pressure difference is nearly 0.1 inches water column at vent area 1 (small area), which is a noticeably high pressure difference (it becomes diffi- 
cult to open or close swinging doors at about this pressure difference). At vent area 2, the static pressure is reduced to below 0.03 inches water column, and, at vent area 3 (the largest), the static pressure difference is reduced to about 0.01 inches water column. Will these low pressure differences cause a problem? The question can be addressed by considering wind-induced pressures, which leads to Fig. 4.

The best way to use Fig. 4 is to start with data as in Fig. 1, anticipated windpressure coefficients. For example, the wind-pressure coefficient on the down wind side of a gable-roof greenhouse is about -0.6. Next, choose a pressure difference. In the example above, vent area 3 imposed a pressure difference of 0.01 inches water column with fan stage 2. Where does the wind create more suction than the fans impose? From Fig. 4. the intersection of a pressure difference of 0.01 inches water column and $\mathrm{C}_{\mathrm{p}}=-0.6$ (same as +0.6 ) is at a wind speed of about $6 \mathrm{mph}$.

Unless windbreaks are planted. averaged yearly wind speeds for many locations in the world are 5 to $10 \mathrm{mph}$. The conclusion is that operation at vent area 3 will lead to air's-exiting the greenhouse through the downwind vents for many hours of the year. If the wind is somewhat gusty, air will alternately enter and leave the greenhouse through the downwind vents area. Admittedly, greater-than-expected air flows will enter the upwind vents, but ventilation air distribution will be distorted severely and temperature sensors may not be located in a zone that reflects the continuously average air temperature of the air space during times of such unbalance. On the other hand, if vent area 1 is used, the ventilation rate will be reduced by a few percent, but the ventilation system will be able to resist wind speeds up to about $18 \mathrm{mph}$, speeds that are exceeded for relatively few hours of the ventilation season in most locations.

Two inlet control strategies are possible to avoid the problem described above. The simplest is to control the inlets to maintain the negative pressure inside the greenhouse within a range. For example, a suitable range might be 0.04 to 0.06 inches water column. On the leeward side, for a wind-pressure coefficient of $-\mathrm{O} .6$, air will not be drawn out the inlet until wind speed is above $11 \mathrm{mph}$. A more complex strategy would be to install an

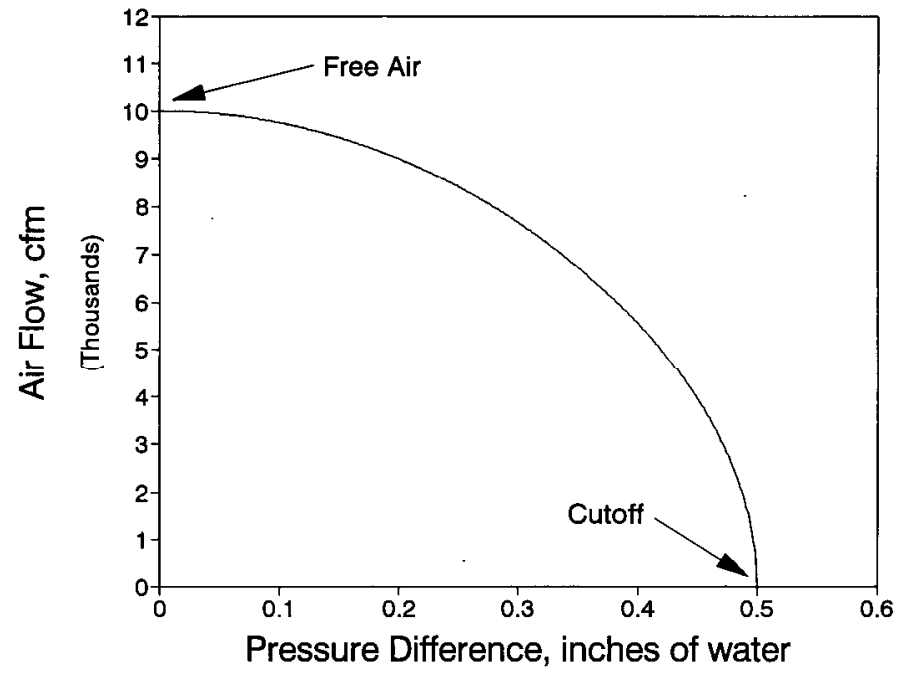

Fig. 2. Example fan characteristic curve showing free air and fan cut-off and relative insensitivity to pressure-difference changes at low-pressure differences. Fan data are hypothetical for illustration only.

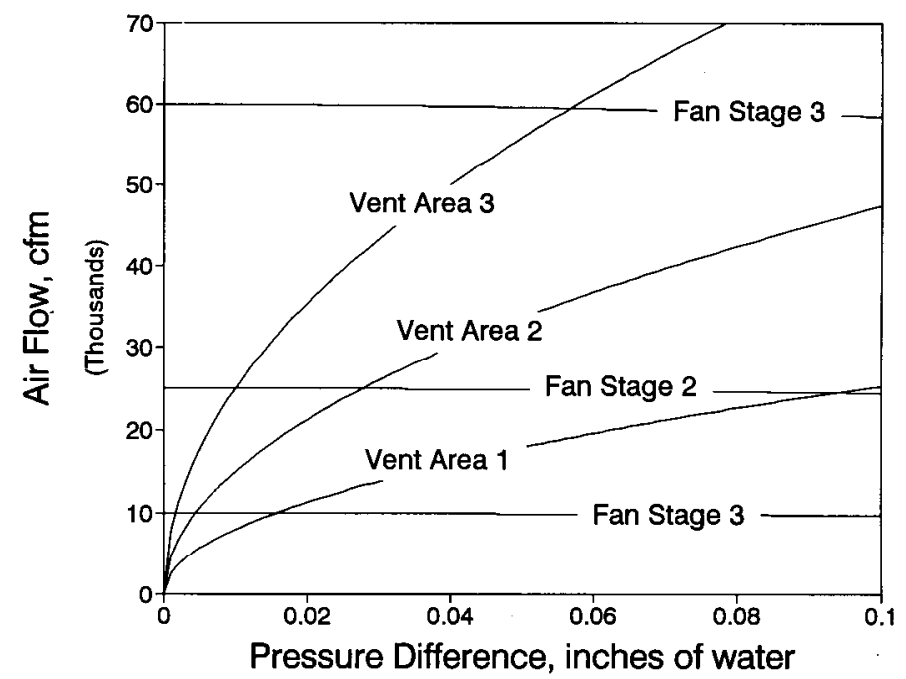

Fig. 3. Example system characteristic graph; coefficient of discharge value is 0.6.

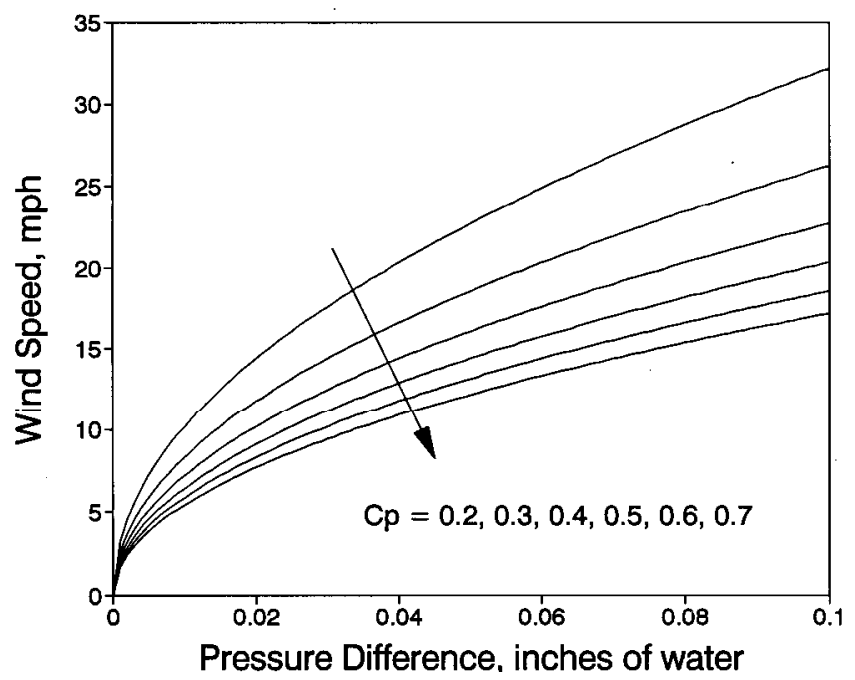

Fig. 4. Wired speed and wind-pressure coefficients required to create a specified static pressure difference. The wind-pressure coefficient and static pressure difference can be either both positive or both negative. 
anemometer (some computerized climate control systems already include them) and use the wind speed, along with Eq. [3], to calculate the negative pressure required in the greenhouse to avoid severe wind problems. A generalized wind-pressure coefficient of 0.6 could be assumed the worst case.

The simpler approach has been used in a five-section research greenhouse on the Cornell Univ. campus. The greenhouse is somewhat shielded from the wind, so a static pressure range of 0.03 to 0.05 inches water column was imposed as permissible for operation of the inlets. A commercially available differential pressure controller (Tuscarora Electric Manufacturing Co., Tunkhannock, Pa. ) was installed in each greenhouse section to control the vents for that section.

Control of the greenhouse inlets was separated from control of the fans. Fans were controlled by air temperature, and inlets opened or closed only when the negative air pressure strayed outside the prescribed range. The system has operated well for nearly 2 years, and temperature control in the greenhouse sections has improved significantly. The vents do not move frequently; the fan stages were chosen with proper step increments and the ventilation rate seldom changes from one extreme value to the other during a short period. Linking inlet control to a climate-control computer is feasible. but the added complication was deemed unnecessary. 'The goal was not to control inlet air velocity to within a narrow range, rather to ensure sufficient air pressure difference and prevent reverse air flow through the inlets. The patterns of air pressures around a structure due to wind make it unlikely that air velocity through all vents can be controlled within a narrow range simultaneously.

In contrast to vent control. conventional greenhouse vent control often begins with the vents opened several inches at the lowest fan stage and ends with vents opened fully at the highest fan stage. This sequence is common for mechanical vent control and operation by climate control computers. The vents on the Cornell research greenhouse, controlled by the pressure sensor, do not open more than a few inches, even during times of greatest ventilation. Such vent areas are sufficient to ensure full ventilation rates, yet wind effects are resisted.

\section{Potential problems}

Two problems must be addressed before inlet control as suggested above can be implemented effectively. The first problem is to find a location relatively unaffected by wind to be the reference atmospheric pressure against which inside air pressure is compared. A differential pressure gauge senses only pressure difference. Indoor pressure acts on one inlet to the gauge; the undisturbed current atmospheric pressure acts on the other. Simple plastic tubing can lead from the sensor to the shielded location and may be many feet long. A possible location is within a shielded box located on a pole above (at least 10 feet) the peak of the greenhouse. The box should be symmetrical, and preferably cylindrical, to equalize wind pressure effects around its perimeter and perforated on all sides for the same reason.

The second problem is more difficult to address. In the analysis and discussion above, planned inlets were the only ones considered. Any air leak is an inlet or outlet, and often the unplanned openings have a combined area greater than that of planned vent openings (unless they are opened wide). Leaks quickly subvert any attempts to control ventilation through modulating the inlets (Albright, 1990). An analogy would be to wire a jumper around a light switch and then try to control the light using the switch.

When the vent-control system was installed in the Cornell greenhouses, it was initially impossible to create a negative pressure as high as 0.01 inches water column with all the fans operating at full speed and the inlets closed. Slipped and broken glass, warped vent sections, holes larger than they need to be for pipe and electric wire entries, doors that do not close tightly, floor drains that are not trapped-the list of possible air leaks seems endless. Many times leaks may not be obvious from visual inspection. A bee smoker can be used very effectively to pinpoint air leaks-close the greenhouse vents, activate the fans, and use puffs of smoke to show where leaks are significant. Such devices are available from firms that sell beekeeping supplies and are inexpensive. More sophisticated smoke-generation devices can be used also; however, smoke bombs are not recommended because they fill the air space with smoke, obscuring vision.
With care, a greenhouse can be sealed sufficiently to permit the fans to draw a partial vacuum on the air space to within the 0.04 to 0.06 inches water column range. The problem becomes one of continual greenhouse maintenance to ensure that leaks do not again predominate in the ventilation rate.

\section{Conclusions}

Greenhouse design has not included sophisticated ventilation inlet control. However, as climate control becomes more precise and responsive (by computers), ventilation control will be inadequate unless inlets buffer the negative effects of wind. Wind effects include reversed air flow through inlets and disrupted air mixing and distribution patterns within the greenhouse air space. Randomly changing air mixing patterns inside a greenhouse can subject temperature sensors to erroneous effects that confuse the control computer-fans control the ventilation rate and inlets control air distribution and internal mixing.

Differential pressure sensors and associated controllers can control ventilation inlets to minimize wind effects. Such control may be integrated into the program for a climate-control computer or may be implemented independently of the computer with little loss of overall effectiveness. However, before such control can be implemented, a serious effort is required to seal the many air leaks that exist in almost all greenhouses (plastic as well as glass). The benefits, in terms of accurate temperature control and proper ventilation system operation, can be substantial.

\section{Literature Cited}

Albright, L.D. 1990. Environment control for animals and plants. Amer. Soc. Agr. Eng.-Soc. for Eng. in Agr., Food, and Biol. Systems, St. Joseph, Mich.

American Society for Heating, Refrigerating, and Air-Conditioning Engineers. 1992. HVAC systems and equipment. Amer. Soc. of Heating, Refrigerating, and Air-Conditioning Eng., Atlanta.

American Society for Heating, Refrigeration, and Air-Conditioning Engineers. 1993. Fundamentals. Amer. Soc. of Heating, Refrigerating, and Air-Conditioning Eng., Atlanta.

Hoxey. R.P. and P. Moran. 1983. A full-scale study of the geometric parameters that influence wind loads on low rise buildings. J. Intl. Wind Eng. Ind. Aerodynamics 13:277-288. 